\title{
The Vietnamese Holistic Mental Well-Being Program in Medical School: Strategies of Social Support, Express Emotion and Problem Avoidance
}

\author{
Quynh, Huynh Ho Ngoc ${ }^{1}$, Tanasugarn, Chanuantong ${ }^{2 *}$, Kengganpanich, Mondha $^{2}$ and Lapvongwatana \\ Punyarat ${ }^{3}$ \\ ${ }^{1}$ Department of Health Education and Psychology in Medicine, Ho Chi Minh City University of Medicine and Pharmacy, Vietnam \\ ${ }^{2}$ Department of Health Education and Behavioral Sciences, Mahidol University, Thailand \\ ${ }^{3}$ Department of Public Health Nursing, Mahidol University, Thailand
}

Submission: February 13 19, 2018; Published: March 13, 2018

*Corresponding author: Chanuantong Tanasugarn, Department of Health Education and Behavioral Sciences, Faculty of Public Health, Mahidol University, Thailand, Tel: +66-0-2354-8543; Email: chanuantong.tan@mahidol.ac.th

\begin{abstract}
This study aimed to develop the mental well-being intervention program to promote Vietnamese medical students mental well-being and to understand their coping strategies when facing stressors. A sequential exploratory mixed-method design was conducted with qualitative study at the first stage and followed by quasi-experimental study. Data collected using in-depth interviews from 16 students and school personnel during the first stage and standard self-administered questionnaires, WHO-5, MHC-SF and CSI were applied in the second stage. Respond rate was $95.7 \%$. Paired-sample t-test showed that students who in intervention group have a chance to increase $1.333 \pm 5.194$ scores on mental wellbeing, increase $0.473 \pm 2.857$ emotional well-being score; $1.488 \pm 5.215$ social well-being score and $0.960 \pm 5.840$ psychological well-being score after attending intervention program. There was significantly increasing in applying strategies of social support, express emotion and problem avoidance among students in intervention group after intervention period at $p=0.021, p=0.002$ and $p<0.001$, respectively. For students who are in the comparison group, the deceasing on applying stress coping strategies of problem solving, cognitive restructuring, express emotion, wishful thinking and self-criticism were found at $\mathrm{p}<0.001$. The higher awareness, earlier intervention activities at school with providing appropriate and accessible support services are recommended to promote Vietnamese medical students' mental well-being. Strengthening personal skills, especially on stress management skills will support Vietnamese medical students better in coping process.
\end{abstract}

Keywords: Mental well-being; Vietnamese medical students; Intervention program; Vanderbilt model; Coping strategies inventory

Abbreviations : CT UMP: Can Tho University of Medicine and Pharmacy; HCMC UMP: Ho Chi Minh University of Medicine and Pharmacy; IRB: Institutional Review Board; MWB: Mental well-being; WHO: World Health Organization; WHO-5: World Health Organization Mental Well-being Scale, 5 items

\section{Introduction}

Mental health was defined by World Health Organization (WHO) as "a state of well-being whereby individuals recognize their abilities, be able to cope with the normal stress of life, work productively and faithfully, and make a contribution to their communities" [1]. About 500 million people suffer from mental disorders worldwide [2]. Young people are more likely to experience mental illness than any other age group [34]. In recent decades, the prevalence of mental health issues among college students have been on rise and it poses a major challenge for public health professionals who are interested in establishing an effective response to these issues [4]. Comparing to other kinds of training, medical training can be seen as one of the most difficulty and pressure training process. Researchers showed that the prevalence of mental disorders among medical students is more likely to be higher than that of other college students as well as the general population [5-7]. Results from literature reviewing provide some important data about mental health situation among medical students around the world such as USA/Europe: 8-15\%, Middle East: 45-67\%, others 21-60\% [8$14]$.

Mental well-being was confirmed that associated with reduced risk of mental disorders, diseases and injury along with create better immune functioning, better coping and quicker recovery and support healthy and long life [15-17]. World Health Organization also recommended that promoting mental health through a focus on key determinants should not only result in 


\section{Global Journal of Pharmacy \& Pharmaceutical Sciences}

lower rates of some mental disorders but also better coping strategies, improved relationship with peers, school members and family [18]. Mental wellbeing of medical students is a very concerned issue because they will become the future health workforce who taking care of people health, both physical and mental.

The ecological model posits that mental well-being outcome is the product of not only one single protective factor, but also multiple factors operating at multiple levels such as individual, interpersonal, and institutional [19]. These determinants shape people lives and some of factors that have important impact on people's mental and physical health. The evidence suggested that different communities or populations have different experiences with the social determinants of mental health [2024]. Therefore, this requires researcher to expand this body of knowledge to deeply understand about the context, the special target population (medical students) and potential solutions at school setting.

Many researchers confirmed that interventions in school setting can provide a healthy environment that supports mental well-being and prevent student from health risk behaviours and suicides [3-25]. The review showed that none of intervention program which using positive approach to promote student's mental health that was conducted in Asia countries; all of existing programs were conducted in the Western context, such as Vanderbilt Medical students Wellness Model (Vanderbilt Model), Mental health Promotion (Cornell Model) and Comprehensive approach to suicide prevention was conducted in United State; UK Healthy Universities model were conducted in England [2633].

In South East Asia countries while many researches were conducted to explore about negative aspects of mental health, such as depression, anxiety and stress, there is not much research was conducted in the positive aspects and its determinant as well as impact on mental health status of people $[20,21,24,34]$. One research was conducted in 2009 showed that the prevalence of depression among medical students was $39.6 \%$ [22]. This number increases to $43.2 \%$ in another research has just published in 2013 [24]. From this research, researchers found that female students had lower well-being than male and first year medical students have a higher risk of depressive symptoms and anxiety than other student in other years. From that result, researchers recommended that medical university leaders should develop counselling and support services for students in early years of the course.

It can be seen that it is much easier to prevent mental disorders from happening than to solve mental disorders after it has already happened. The evidences suggested that promote good mental well-being will prevent mental disorder to happen; and to prevent mental disorder from happening, intervention activities should focus on controlling stressors and strengthening people's coping ability [35,36]. Unfortunately, in Vietnam, intervention to promote mental well-being has never existed, especially in the school setting. Therefore, the strategy to strengthening student's coping ability will be applies in this study to promote mental well-being of medical student in medical school.

Consequently, because of the limited research in this area in Vietnam, this study was designed to explore the context and factors that related to mental health and well-being of Vietnamese medical students; to understand stress coping strategies that were applied when facing stressors and to aid the development of the wellness intervention program to promote medical students mental well-being. Components of intervention program are strongly linked to medical students' perceived needs. By applying the ecological approach to medical student mental health, we hope to broaden the perspective beyond individualistic explanations, increase awareness of students and school members about the mental health problem and mental well-being approach, enhance personal stress management skills and take into consideration broader environmental level influences.

\section{Methods}

This sequential exploratory mixed-method research initially involved a qualitative study and followed by a quasi-experimental study. The qualitative stage involved 16 in-depth interviews of medical students from different years and faculty personnel. The interviews were carried out based on guidelines developed to capture the context and factors that potentially impact on students' mental well-being. Moreover, student's needs and recommended solutions were also identified at this stage. Qualitative data analysed using theme analysis method. Based on qualitative results, intervention activities were developed to promote student's mental well-being for the second stage. First year medical students were identified as intervention target population. All first year students were invited into mental well-being screening test which measured by World Health Organization Well-being scale (WHO-5) [37].

The eligibility criteria for the intervention group were students who have age range 18 and above and have mental well-being score under 13 or has answered 0 to 1 to any of the five items of WHO-5 scale. 210 students at Ho Chi Minh City University of Medicine and Pharmacy (HCMC UMP) were chosen. Another 210 participants in the comparison group at CT UMP were chosen by matching gender and mental well-being score. The changing on mental well-being index of medical students after the intervention period was collected to identify the effect of intervention program on students' mental well-being. Pre-test and post-test quantitative data was analysed using independent t-test and paired-sample t-test to identify the mean score difference within and between groups. From these results, the effect of the Wellness intervention program was confirmed.

This research got approval of Institutional Review Boards (IRB) of Mahidol University and HCMC UMP. Besides, informed consent was obtained to ensure that the participant has been fully informed about the research, its benefits as well as risks. 


\section{Global Journal of Pharmacy \& Pharmaceutical Sciences}

Anonymity by name coding and confidentiality was emphasized. No name was used in the final write-up of the study.

\section{Results}

\section{Factors influencing medical students' mental well- being}

Both students and school personnel perceived that there were many factors at intrapersonal level that potential influenced on medical student's mental health and it played an important role in developing personal abilities to cope with stressors during medical study process and to promote their positive mental health (Table 1). Factors of interpersonal and institutional levels played supportive role on reinforcing and maintaining student's good mental health status. Students concerned more on personal skills development, academic environment, attractive extra-curriculum activities, and multiform of student support services while school personnel expressed their concern on student's personal skills, family issues, infrastructure and teacher resource.

Table 1: Summarize factors which impact on medical student's mental well-being, perceived by students and school personnel.

\begin{tabular}{|c|c|c|c|}
\hline Levels & $\begin{array}{l}\text { Factors Which Potential } \\
\text { Impact on Student's Mental } \\
\text { Well-Being }\end{array}$ & Perceived by Students & $\begin{array}{l}\text { Perceived by School } \\
\text { Personnel }\end{array}$ \\
\hline \multirow{11}{*}{ Intrapersonal level } & 1. Academic performance & $\mathrm{P}$ & \\
\hline & 2. Goal setting & $\mathrm{P}$ & $\mathrm{P}$ \\
\hline & $\begin{array}{l}\text { 3. Career motivation and } \\
\text { expectation }\end{array}$ & $P$ & $P$ \\
\hline & 4. Personality & $P$ & $P$ \\
\hline & 5. Study skills & $\mathrm{P}$ & $\mathrm{P}$ \\
\hline & 6. Communication skill & $P$ & \\
\hline & 7. Self-efficacy & $\mathrm{P}$ & \\
\hline & 8. Life skill & $\mathrm{P}$ & $\mathrm{P}$ \\
\hline & 9. Emotion & $P$ & $P$ \\
\hline & 10. Stress adaptability & $\mathrm{P}$ & $\mathrm{P}$ \\
\hline & 11. Life styles & $\mathrm{P}$ & $\mathrm{P}$ \\
\hline \multirow{7}{*}{ Interpersonal level } & $\begin{array}{l}\text { 1. Peer and senior } \\
\text { relationships }\end{array}$ & $P$ & $P$ \\
\hline & 2. Family relationship & $\mathrm{P}$ & $\mathrm{P}$ \\
\hline & 3. Family economic status & $\mathrm{P}$ & $P$ \\
\hline & 4. Family expectation & $\mathrm{P}$ & $\mathrm{P}$ \\
\hline & $\begin{array}{l}\text { 5. Boy or girlfriend } \\
\text { relationship }\end{array}$ & $\mathrm{P}$ & \\
\hline & $\begin{array}{l}\text { 6. Social communication and } \\
\text { relationships }\end{array}$ & $P$ & $P$ \\
\hline & $\begin{array}{l}\text { 7. Perceived social taboo } \\
\text { towards "mental disorders" }\end{array}$ & $\mathrm{P}$ & \\
\hline \multirow{6}{*}{ Institutional level } & 1. Academic environment & $\mathrm{P}$ & $\mathrm{P}$ \\
\hline & $\begin{array}{l}\text { 2. Facilities for physical } \\
\text { activities }\end{array}$ & $\mathrm{P}$ & $P$ \\
\hline & 3. School built environment & $\mathrm{P}$ & $\mathrm{P}$ \\
\hline & 4. Extra-curriculum activities & $\mathrm{P}$ & $\mathrm{P}$ \\
\hline & $\begin{array}{l}\text { 5. Current policies and } \\
\text { support services }\end{array}$ & $\mathrm{P}$ & $P$ \\
\hline & 6. School reputation & $P$ & \\
\hline
\end{tabular}

\section{The Mental well-being intervention program and} activities

In exploring the determinants of medical student's mental well-being and needs assessment results which were collected from phase 1 and the characteristics of successful mental health promotion programs, research team not only worked with medical students but also discussed with faculty administrators and the university president to decide which components and activities should be include in this intervention program to fix with the medical school current situation. This mental wellbeing program was the first intervention program that was implemented in Vietnam medical school and sought to promote 
student's mental well-being (Figure 1). Activities in program were classified into three levels of intrapersonal, interpersonal and institutional level. However, based on the current situation of Vietnamese medical school, activities at intrapersonal level were more concentrated.

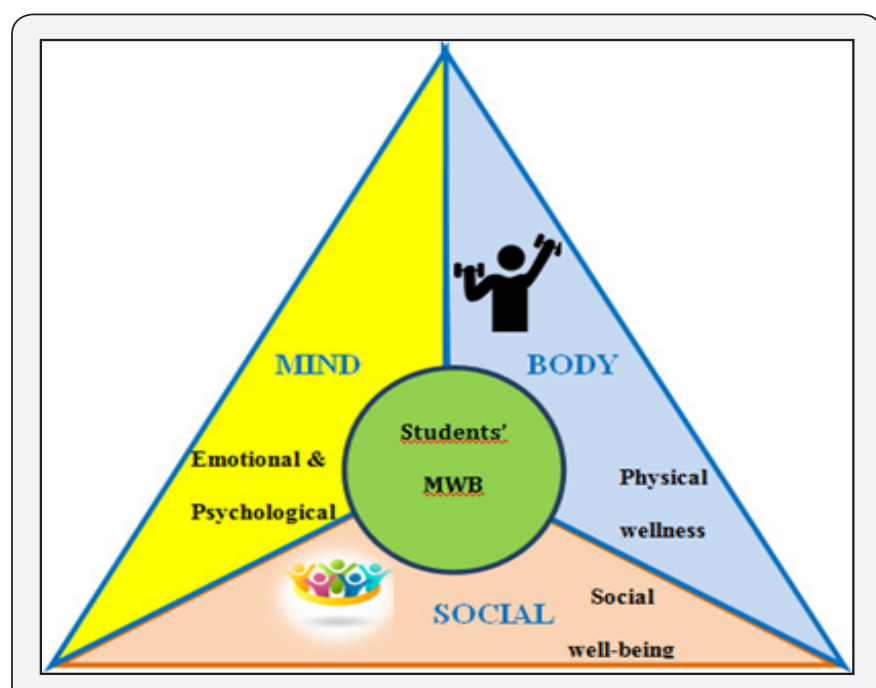

Figure 1: The Vietnamese mental well-being intervention model.

Individual level interventions: The wellness intervention activities which emphasized on the individual level to explore the current strategies that medical students currently applied to stress situations; then strengthen their abilities on dealing with stressors during study process and promote positive emotions. The skill trainings were designed to promote effective time management, communication skill, problem-solving skill, and especially stress management skills.

In skill training sessions, speaker supported and guided students to adjust their own plan to adapt with new study environment. Speaker acting as the medical student role model was applied to demonstrate study strategies as well as adjustment skills from medical students to medical professional. First year medical students who were invited in attending workshop were encouraged to attend in interaction activities of workshop training sessions. Moreover, there was a support group which included students from student association unit participated in each sessions to provide support in organizing ice-break activities and ready to share experiences in dealing with difficulty situations during the study process. The present of this group were important and partly contributed to strengthen the relationship between the first year students and the senior years.

Interpersonal level interventions: Finding from phase 1 indicated that social relationship among students and others including family members and friend and social expectations brought a lot of pressure to medical students. Intervention activities at this level were designed to improve students' sense of social belonging; promoting peer networks were helpful in supporting mental well-being. After the Friendship camping, first year students were asked about the connection with seniors. Students who had no connection yet with one or more seniors at other years will be partnered with seniors from the Student Association Unit. Students who already had some connectedness with seniors were encouraged to continuing their relationship. Practical results showed that almost the first year students reported that they received encouragements, advices and also "study tips" from the seniors. Students were encouraged to assign themselves in medical school clubs, both academic and non-academic clubs.

Institutional level interventions: Poor mental well-being is consistently associated with poor school climate, current policies and student support services. Counseling service was run aim to improve student support services which support students' mental well-being. Moreover, a mobile phone application named ThamVan $24 \times 7$ was developed to increase the accessibility of counseling activities to medical students.

\section{The effect of the mental well-being intervention program on promoting medical students' mental well-being}

The paired-samples t-test was performed to determine whether there is a statistically significant difference between the mean scores within group (Table 2). Analysis results on WHO-5 scale showed that there was a significant improvement in mental well-being score of students who attended in intervention group $13.61 \pm 5.776$ than before intervention $12.28 \pm 5.223, t(200)=-$ $3.640, \mathrm{p}<0.001$. Students who were in the intervention group have a chance to increase $1.333 \pm 5.194$ scores on mental wellbeing index after attending the intervention program. Moreover, the statistical tests also revealed that there was significant improvement in emotional well-being, social well-being and psychological well-being score after intervention. Students were in the intervention group have a chance to increase $0.473 \pm 2.857$ emotional well-being score; $1.488 \pm 5.215$ social well-being score and $0.960 \pm 5.840$ psychological well-being score after attending intervention program. Additionally, there was a statistical decrease on psychological well-being score of students who in comparison group at $\mathrm{p}=0.005$.

The mean, standard deviation, and median from total scores obtained on the scales and sub-scales of the Coping Strategies Inventory (CSI) scale were summarized in Table 3. There were eight primary scales which reflected the coping strategies that medical students use in response to stressful events, such as problem solving, cognitive restructuring, social support, express emotion, problem avoidance, wishful thinking, self-criticism and social withdrawal. Higher score on CSI scale represent higher use of each coping strategy. 


\section{Global Journal of Pharmacy \& Pharmaceutical Sciences}

Table 2: The result of paired-sample t-test on student's mental well-being score between intervention and comparison group.

\begin{tabular}{|c|c|c|c|c|c|c|c|}
\hline $\begin{array}{l}\text { Mental well- } \\
\text { being }\end{array}$ & $\begin{array}{c}\text { Paired } \\
\text { Difference }\end{array}$ & & & & $\mathbf{t}$ & df & $\mathbf{p}$ \\
\hline & Mean \pm SD & Mean \pm SD & \multicolumn{2}{|c|}{$95 \%$ CI of the Difference } & & & \\
\hline & & & Lower & Upper & & & \\
\hline \multicolumn{8}{|l|}{$\begin{array}{l}\text { Intervention } \\
\text { group }\end{array}$} \\
\hline MWB_pre & $12.28 \pm 5.223$ & $1.333 \pm 5.194$ & -2.056 & -0.611 & -3.64 & 200 & $<0.001^{*}$ \\
\hline MWB_post & $13.61 \pm 5.776$ & & & & & & \\
\hline \multicolumn{8}{|l|}{$\begin{array}{l}\text { Comparison } \\
\text { group }\end{array}$} \\
\hline MWB_pre & $11.37 \pm 5.344$ & $0.14 \pm 4.779$ & -0.664 & -0.636 & -0.043 & 209 & 0.965 \\
\hline MWB_post & $11.38 \pm 5.197$ & & & & & & \\
\hline \multicolumn{8}{|c|}{ Emotional Well-being } \\
\hline \multicolumn{8}{|l|}{$\begin{array}{l}\text { Intervention } \\
\text { group }\end{array}$} \\
\hline EWB_pre & $9.14 \pm 2.709$ & $0.473 \pm 2.857$ & -0.87 & -0.075 & -2.346 & 200 & $0.020^{*}$ \\
\hline EWB_post & $9.61 \pm 3.048$ & & & & & & \\
\hline \multicolumn{8}{|l|}{$\begin{array}{l}\text { Comparison } \\
\text { group }\end{array}$} \\
\hline EWB_pre & $8.60 \pm 3.147$ & $0.176 \pm 3.015$ & -0.234 & 0.586 & 0.847 & 209 & 0.398 \\
\hline EWB_post & $8.43 \pm 3.205$ & & & & & & \\
\hline \multicolumn{8}{|c|}{ Social Well-Being } \\
\hline \multicolumn{8}{|l|}{$\begin{array}{l}\text { Intervention } \\
\text { group }\end{array}$} \\
\hline SWB_pre & $13.38 \pm 4.931$ & $1.488 \pm 5.215$ & -2.213 & -0.762 & -4.044 & 200 & $<0.001^{*}$ \\
\hline SWB_post & $14.87 \pm 5.041$ & & & & & & \\
\hline \multicolumn{8}{|l|}{$\begin{array}{l}\text { Comparison } \\
\text { group }\end{array}$} \\
\hline SWB_pre & $12.24 \pm 5.102$ & $0.214 \pm 4.818$ & & & 0.645 & 209 & 0.52 \\
\hline SWB_post & $12.03 \pm 5.057$ & & -0.441 & 0.87 & & & \\
\hline \multicolumn{8}{|c|}{ Psychological Well-Being } \\
\hline \multicolumn{8}{|l|}{$\begin{array}{l}\text { Intervention } \\
\text { group }\end{array}$} \\
\hline PWB_pre & $18.47 \pm 5.930$ & & & & & & \\
\hline PWB_post & $19.43 \pm 5.922$ & $0.960 \pm 5.840$ & -1.772 & -0.148 & -2.331 & 200 & $0.021^{*}$ \\
\hline \multicolumn{8}{|l|}{$\begin{array}{l}\text { Comparison } \\
\text { group }\end{array}$} \\
\hline PWB_pre & $17.90 \pm 6.676$ & & & & & & \\
\hline PWB_post & $16.63 \pm 66.396$ & $1.276 \pm 6.508$ & 0.391 & 2.162 & 2.842 & 209 & $0.005^{*}$ \\
\hline
\end{tabular}




\section{Global Journal of Pharmacy \& Pharmaceutical Sciences}

Table 3: The results of Paired samples t-test on coping strategies that medical students used in response to stressful events.

\begin{tabular}{|c|c|c|c|c|c|c|c|}
\hline \multirow{3}{*}{$\begin{array}{c}\text { Coping } \\
\text { Strategies }\end{array}$} & \multirow[t]{3}{*}{ Mean \pm SD } & \multicolumn{3}{|c|}{ Paired Differences } & \multirow[t]{3}{*}{$\mathbf{t}$} & \multirow[t]{3}{*}{ df } & \multirow[t]{3}{*}{$\mathbf{p}$} \\
\hline & & $\begin{array}{c}\text { Mean } \\
\text { difference }\end{array}$ & \multicolumn{2}{|c|}{ 95\%CI of Difference } & & & \\
\hline & & & Lower & Upper & & & \\
\hline \multicolumn{8}{|c|}{ Problem Solving Strategy } \\
\hline \multicolumn{8}{|l|}{$\begin{array}{l}\text { Intervention } \\
\text { group }\end{array}$} \\
\hline Pre-test & $32.62 \pm 5.224$ & $0.557 \pm 5.814$ & -0.252 & 1.366 & 1.359 & 200 & 0.176 \\
\hline Post-test & $32.06 \pm 5.497$ & & & & & & \\
\hline \multicolumn{8}{|l|}{$\begin{array}{c}\text { Comparison } \\
\text { group }\end{array}$} \\
\hline Pre-test & $33.29 \pm 5.376$ & $1.929 \pm 5.410$ & 1.193 & 2.664 & 4.118 & 209 & $<0.001$ \\
\hline Post-test & $31.36 \pm 5.503$ & & & & & & \\
\hline \multicolumn{8}{|c|}{ Cognitive Restructuring Strategy } \\
\hline \multicolumn{8}{|l|}{$\begin{array}{l}\text { Intervention } \\
\text { group }\end{array}$} \\
\hline Pre-test & $32.14 \pm 4.997$ & $-0.105 \pm 5.928$ & -0.932 & 0.722 & -0.25 & 200 & 0.802 \\
\hline Post-test & $32.24 \pm 5.347$ & & & & & & \\
\hline \multicolumn{8}{|l|}{$\begin{array}{c}\text { Comparison } \\
\text { group }\end{array}$} \\
\hline Pre-test & $32.17 \pm 5.453$ & $1.708 \pm 5.997$ & 0.89 & 2.526 & 4.118 & 209 & $<0.001$ \\
\hline Post-test & $30.46 \pm 5.063$ & & & & & & \\
\hline \multicolumn{8}{|c|}{ Social Support Strategy } \\
\hline \multicolumn{8}{|l|}{$\begin{array}{l}\text { Intervention } \\
\text { group }\end{array}$} \\
\hline Pre-test & $28.74 \pm 6.448$ & $1.000 \pm 6.107$ & -1.849 & -0.151 & -2.321 & 200 & 0.021 \\
\hline Post-test & $29.74 \pm 6.419$ & & & & & & \\
\hline \multicolumn{8}{|l|}{$\begin{array}{l}\text { Comparison } \\
\text { group }\end{array}$} \\
\hline Pre-test & $27.01 \pm 6.836$ & $0.348 \pm 6.605$ & -0.551 & 1.246 & 0.763 & 209 & 0.447 \\
\hline Post-test & $26.66 \pm 6.706$ & & & & & & \\
\hline \multicolumn{8}{|c|}{ Express Emotions Strategy } \\
\hline \multicolumn{8}{|l|}{$\begin{array}{l}\text { Intervention } \\
\text { group }\end{array}$} \\
\hline Pre-test & $27.61 \pm 4.512$ & $1.169 \pm 5.314$ & -1.908 & -0.43 & -3.119 & 200 & 0.002 \\
\hline Post-test & $28.78 \pm 4.588$ & & & & & & \\
\hline \multicolumn{8}{|l|}{$\begin{array}{l}\text { Comparison } \\
\text { group }\end{array}$} \\
\hline Pre-test & $28.53 \pm 4.840$ & $0.762 \pm 5.229$ & 0.361 & 0.051 & 1.473 & 209 & 0.036 \\
\hline Post-test & $27.77 \pm 4.777$ & & & & & & \\
\hline \multicolumn{8}{|c|}{ Problem Avoidance Strategy } \\
\hline \multicolumn{8}{|l|}{$\begin{array}{l}\text { Intervention } \\
\text { group }\end{array}$} \\
\hline Pre-test & $24.87 \pm 5.381$ & $1.945 \pm 5.526$ & -2.714 & -1.177 & -4.991 & 200 & $<0.001$ \\
\hline Post-test & $26.81 \pm 4.922$ & & & & & & \\
\hline \multicolumn{8}{|l|}{$\begin{array}{l}\text { Comparison } \\
\text { group }\end{array}$} \\
\hline Pre-test & $26.49 \pm 5.090$ & $0.100 \pm 5.347$ & -0.641 & 0.842 & 0.267 & 209 & 0.79 \\
\hline
\end{tabular}




\section{Global Journal of Pharmacy \& Pharmaceutical Sciences}

\begin{tabular}{|c|c|c|c|c|c|c|c|}
\hline Post-test & $26.39 \pm 5.361$ & & & & & & \\
\hline \multicolumn{8}{|c|}{ Wishful Thinking Strategy } \\
\hline \multicolumn{8}{|c|}{$\begin{array}{l}\text { Intervention } \\
\text { group }\end{array}$} \\
\hline Pre-test & $27.90 \pm 6.303$ & $0.070 \pm 6.322$ & -0.81 & 0.949 & 0.156 & 200 & 0.876 \\
\hline Post-test & $27.83 \pm 5.965$ & & & & & & \\
\hline \multicolumn{8}{|c|}{$\begin{array}{l}\text { Comparison } \\
\text { group }\end{array}$} \\
\hline Pre-test & $30.99 \pm 6.527$ & $1.785 \pm 6.110$ & 0.951 & 2.618 & 4.223 & 209 & $<0.001$ \\
\hline Post-test & $29.20 \pm 6.405$ & & & & & & \\
\hline \multicolumn{8}{|c|}{ Self-Criticism Strategy } \\
\hline \multicolumn{8}{|c|}{$\begin{array}{l}\text { Intervention } \\
\text { group }\end{array}$} \\
\hline Pre-test & $25.21 \pm 7.287$ & $0.667 \pm 7.721$ & -1.741 & 0.407 & -1.224 & 200 & 0.222 \\
\hline Post-test & $26.88 \pm 6.594$ & & & & & & \\
\hline \multicolumn{8}{|l|}{$\begin{array}{l}\text { Comparison } \\
\text { group }\end{array}$} \\
\hline Pre-test & $28.25 \pm 7.674$ & $1.719 \pm 6.790$ & 0.795 & 2.643 & 3.669 & 209 & $<0.001$ \\
\hline Post-test & $26.53 \pm 7.289$ & & & & & & \\
\hline \multicolumn{8}{|c|}{ Social Withdrawal Strategy } \\
\hline \multicolumn{8}{|l|}{$\begin{array}{l}\text { Intervention } \\
\text { group }\end{array}$} \\
\hline Pre-test & $23.87 \pm 6.927$ & $0.274 \pm 6.629$ & -1.196 & 0.648 & -0.585 & 200 & 0.559 \\
\hline Post-test & $24.14 \pm 6.413$ & & & & & & \\
\hline \multicolumn{8}{|l|}{$\begin{array}{l}\text { Comparison } \\
\text { group }\end{array}$} \\
\hline Pre-test & $26.60 \pm 6.811$ & $0.338 \pm 5.919$ & -0.467 & 1.143 & 0.828 & 209 & 0.409 \\
\hline Post-test & $26.26 \pm 6.468$ & & & & & & \\
\hline
\end{tabular}

The paired sample t-test showed that there was significantly increasing in applying social support, express emotion and problem avoidance as their coping methods in the intervention group after intervention period at $\mathrm{p}=0.021, \mathrm{p}=0.002$ and $\mathrm{p}<0.001$, respectively. For students who were in the comparison group, the deceasing on applying stress coping strategies of problem solving $(\mathrm{p}<0.001)$, cognitive restructuring $(\mathrm{p}<0.001)$, express emotion $(p=0.036)$, wishful thinking $(p<0.001)$ and selfcriticism $(p<0.001)$ were found.

\section{Discussion}

The results indicated that medical student's mental health in Vietnam is influenced by a wide range of factors, including personal factors, family, school and social factors and potential professional consequences. Some are barriers of mental wellbeing, some can encouraging. These findings are similar with things that were found by many researchers from 2007 to 2013 [38-42].

\section{The effect of the mental well-being intervention program}

This mental well-being intervention program should not be a replacement the existing supportive services that available for medical students, but rather to complement and strengthen the existing student support activities and services. Besides, the mental well-being model was built based on the ecological model of public health which views the mental well-being as a holistic concept determined by a complex interaction of individual, environmental and institutional factors. Results of this present study will contribute to the understanding of mental health of medical student in Vietnam more broadly in the positive aspect.

Additionally, it can be said that this intervention design is in lined with conformable with the recommendations from many researches which were conducted in the Western countries and Malaysia. Those researchers recommended that medical school should help medical students in coping strategies to handle problems, changes and promote positive mental health via personal skills development to help them detect their own problems, proper evaluation of the problem and taking appropriate actions to handle the problems and self-improvement from the problems [26,43-45]. Therefore, different from current models in the literature, these Wellness model activities are more focuses on the intrapersonal level. Additionally, the mental well-being program design is consistent with the emphasis of World Health Organization "mental health promotion involves promoting the value for mental health 
and improving the coping capacities of individuals rather than amelioration of symptoms and deficits" [46].

In comparing to current models, because of the difference on culture and society, Western students were empowered on the personal skills, such as active study skills and life skills, since they were children. Therefore, institutional approach in the Western schools seem to be affective being environment influencing factor can support student' mental well-being better. Moreover, campaigns to ensure the healthy educational environment at the community and policy level were also provided. Those current models were proved that have particular impact on student's mental well-being.

This research results showed that students in the intervention group have a chance to increase mental well-being, emotional well-being, social well-being and psychological wellbeing scores comparing to those in the comparison group. This means the mental well-being intervention compared with no intervention has consistent positive effects on medical students' mental well-being. Due to the difference on the large scale of intervention and also the length of intervention, the selected outcome in Drolet et al. [26] research at Vanderbilt school of medicine and in this current research is different [47]. However, these research findings are similar with a meta-analysis on interventions on medical student's psychological health which was conducted by Yusoff [48]. In Yusoff research, stress management interventions which were analyzed in the metaanalysis brought benefit to medical students' mental well-being in comparison with no intervention.

\section{Strategies of social support, express emotion and problem avoidance}

Researchers at Western countries and Malaysia recommended that medical schools should help medical students learn strategies that handle problems and promote positive mental health via personal skills development to let them detect their own problems, proper evaluation of the problem and taking appropriate actions to handle the problems and self-improvement from the problems [26,43-45]. Findings from this research showed that lacking of life skills, study skills and communication skills contributed to student poor mental wellbeing and also negatively influent to their stress adaptability. These factors were not mentioned in previous researches review. This may be due to the difference in educational philosophy and cultural issues between Western and Eastern countries. Westerners stress active learning on their learners, whereas the Easterners prefer passive learning. Western educational system encourages the students to be active in giving and sharing the ideas, which maximizes their roles in learning and doing things independently even when they were children.

Soft skills were trained by encouraging students to attend in social or voluntary activities. Students also have been encouraged to express their ability and talent by analysing and solving problems on their own. Therefore, it can be said that in the Western countries, students were empowered by promoting thinking skills, problem solving and communication skills. On the contrary, in Eastern countries, students were not trained or required to do anything. At school, all the materials are given by teachers. Usually, students are not required to carry out any research on the topics that are going to be discussed in the next lesson, but only responsible to receive input from their teachers. Besides, students are not trained or encouraged to voice out their own views and perspectives. These happened for a long time since students were child and gradually limited their personal skills development. Therefore, when entering to the new environment at medical school, the lacking of those skills become barriers to students' coping adaptability and mental well-being.

Research results showed that having good skills on managing stress supports Vietnamese medical students in problem solving and make them happier. Vietnamese medical students tend to apply both problem focused on engagement and disengagement strategies to adapt with stressful events happened during the study process. Some of them actively act on stress situation by trying to think differently about the stress situation, looking as the positive aspects of the problem to make it less threatening. HCMC UMP medical students tend to release and express emotions with friends, family and others when they face with problems. Once they could not find solutions, they refer to seek emotion supports from others who surround them, especially from friends and family members. These findings are consistent with the review of Fares et al.'s findings in 2016. Fares et al. who reported that the medical students, especially preclinical students applied strategies that involve engagement such as problem solving, positive reinterpretation and expression of emotion to adapt with stressful situations and its effects on mental wellbeing [49].

Another research in Ohio also reported that medical students generally used active coping strategies, such as positive reframing, planning, acceptance, self-distraction, and emotional support [50]. It can be said that helping medical students cultivate the skills to sustain their well-being throughout the study process has important impact on the overall medical education enterprise to increase student self-efficacy and personal fulfilment. However, some of them are quite passive. They try to avoid thinking or acting about the stressful events. Medical students from comparison group at CT UMP tend to apply cognitive strategies that alter the meaning of the stressful transaction as it is less threatening. They used to criticize and blame themselves for what happened and also hope and wish that bad situation could be better.

This is the first multi-levels intervention study which was conducted at medical university setting in Vietnam. Intervention activities were developed based on the medical needs and the consent of school administrators. All activities were discussed 


\section{Global Journal of Pharmacy \& Pharmaceutical Sciences}

carefully from both sides before implementing. The high response rates and a complete capture of the medical student population removes general sources of bias and errors that can occur in the sampling duration and increases the validity of inference drawn from study [51]. This study conceptualized mental health quite broadly, including both positive and negative outcome. Though research target on positive outcome, this makes a unique contribution because most studies only focus on the negative aspects of mental health outcomes. Standardized and valid measurement scales which were applied in this research ensured the quality of research results $[24,52,53]$.

Besides notable strengths, this research has limitations. This research was going to prove the impact of intervention program and was not going to confirm the determinants of mental wellbeing. This limits the generalizability of research findings on multi-level factors that actually impact on student's mental well-being. The research is the first mental health promotion intervention in this special population of Vietnamese medical students; there is no previous data to make a comparison in intervention program developing process.

\section{Conclusion}

In conclusion, medical school intervention to promote mental well-being in the Vietnamese medical schools is needed though mental well-being is still not a familiar concept with Vietnamese medical students. The mental well-being of Vietnamese medical students was influenced by many factors at different level and it impacts on different aspects of student life, including health, social relationship, academic achievement and quality of life. Recognizing threatening factors and facilitating factors at each level of intervention will support researchers in implementing intervention to promote better students' mental well-being. Strengthening personal skills, especially on stress management skills for Vietnamese medical students will support them better in coping process. Encouraging peer support activities and improve medical school environment, both academic and physical environment, will foster medical student actively attended in mental health promotion activity and then improve their quality of life during study process at medical school. Higher awareness, earlier intervention activities maintaining a continuing appropriate and accessible support services are crucial. Maintaining intervention activity is needed to promote mental well-being of Vietnamese medical students. In the long run, such efforts will benefit the broader public and society, as well as bringing benefits to individual students in need of support.

\section{Acknowledgement}

This research was partially supported by WHO Western Pacific Region. The authors gratefully acknowledge the time and effort given by the medical students, universities administrators, and a core group of passionate students and school teachers of HCMC UMP and CT UMP to our studies.

\section{References}

1. World Health Organisation (2008) WHO urges more investments, services for mental health.

2. World Health Organisation (2015) Department of Mental Health and Substance Abuse.

3. Hanlon C (2012) State of mind-Addressing mental health issues on university campuses.

4. Melo-Carrillo A, Van-Oudenhove L, Lopez-Avila A (2012) Depressive symptoms among Mexican medical students: High prevalence and the effect of a group psychoeducation intervention. Journal of Affective Disorders 136(3): 1098-1103.

5. Tempski P, Bellodi PL, Paro HB, Enns SC, Martins MA, et al. (2012) What do medical students think about their quality of life? A qualitative study. BMC Med Educ 12: 106.

6. Biro E, Balajti I, Adany R, Kosa K (2010) Determinants of mental wellbeing in medical students. Soc Psychiatry Psychiatr Epidemiol 45(2): 253-258.

7. Demirbatir RE (2012) Undergraduate Music Student's Depression, Anxiety and Stress Levels: A Study from Turkey. Procedia - Social and Behavioral Sciences 46(2): 2995-2999.

8. Morrison W, Kirby P (2010) Schools as a Setting for Promoting Positive Mental Health: Better Practices and Perspectives. Canada: Joint Consortium for School Health; New York, USA, p. 1-82.

9. Aktekin M, Karaman T, Senol Y, Erdem S, Erengin HMA (2001) Anxiety, depression and stressful life events among medical students: a prospective study in Antalya, Turkey. Med Educ 35(1): 12-7.

10. Dyrbye LN, Thomas MR, Shanafelt TD (2005) Medical Student Distress: Causes, Consequences, and Proposed Solutions. Mayo Clinic Proceedings 80(12): 1613-1622.

11. Toews J, Lockyer J, Dobson D, Simpson E, Brownell AK, et al. (1997) Analysis of stress levels among medical students, residents, and graduate students at four Canadian schools of medicine. Acad Med 72(11): 997-1002.

12. Zeldow PB, Clark DC, Daugherty SR, Eckenfels EJ (1985) Personality indicators of psychosocial adjustment in first-year medical students. Social Science \& Medicine 20(1): 95-100.

13. Castaldelli-Maia JoMc, Martins SS, Bhugra D, Machado MP, Andrade AG, et al. (2012) Does ragging play a role in medical student depression? Cause or effect? Journal of Affective Disorders 139(3): 291-297.

14. Amrai K, Zalani HA, Arfai FS, Sharifian MS (2011) The relationship between the religious orientation and anxiety and depression of students. Procedia - Social and Behavioral Sciences 15: 613-616.

15. Shamsuddin K, Fadzil F, Ismail WSW, Shah SA, Omar K, et al. (2013) Correlates of depression, anxiety and stress among Malaysian university students. Asian Journal of Psychiatry 6(4): 318-323.

16. Xu Y, Chi X, Chen S, Qi J, Zhang P, et al. (2014) Prevalence and correlates of depression among college nursing students in China. Nurse Education Today 34(6): e7-e12.

17. Kobau R, Bann C, Lewis M, Zack MM, Boardman AM, et al. (2010) Mental, social, and physical well-being in New Hampshire, Oregon, and Washington, 2010 Behavioral Risk Factor Surveillance System: implications for public health research and practice related to Healthy People 2020 foundation health measures on well-being. Population health metrics 11(1): 19 .

18. World Health Organisation (2005) Promoting Mental Health: Concepts, emerging evidence and Practice. Geneva: Department of Mental Health and Substance Abuse, The Victorian Health Promotion Foundation, The University of Melbourne, Victoria, Australia, p. 1-70 


\section{Global Journal of Pharmacy \& Pharmaceutical Sciences}

19. Byrd DR, McKinney KJ (2012) Individual, Interpersonal, and Institutional Level Factors Associated With the Mental Health of College Students. Journal of American College Health 60(3): 185-194.

20. Quynh HHN, Dunne M (2010) Mental health issues of Public Health and Nursing students in Ho Chi Minh City in 2009. Ho Chi Minh City Journal of Medicine 14(1): 95-100.

21. Dang TN, Dung DV, Quynh HHN (2011) The prevalence of mental disorders among Public Health students in 2010. Ho Chi Minh City Journal of Medicine 15(1): 62-67.

22. Quyen DD, Tasanapradit P (2008) Depression and stress among the first year medical students in university of Medicine and Pharmacy, Ho Chi Minh City, Vietnam. Journal of Health research 22: 1-4.

23. Anh Tran Q Dunne M, Thang TB, Van TV, Anh TDT (2012) Depression, suicidal ideation and anxiety among university students in central Vietnam: Prevalence and possible contributing factors.

24. Anh TQ, Dunne MP, Hoat LN (2013) Well-being, depression and suicidal ideation among medical students throughout Vietnam. Vietnam Journal of Medicine and Pharmacy 5(2): 1-10.

25. Wisessathorn M, Tanasugarn C, Fisher EB (2013) The impact of child's severity on quality-of-life among parents of children with autism spectrum disorder: the mediating role of optimism. J Med Assoc Thai 96(10): 1313-1318

26. Drolet BC, Rodgers S (2010) A Comprehensive Medical Student Wellness Program-Design and Implementation at Vanderbilt School of Medicine. Academic Medicine 85(1): 103-110.

27. Yusoff MSB, Mat Pa MN, Esa AR, Abdul Rahim AF (2013) Mental health of medical students before and during medical education: $A$ prospective study. Journal of Taibah University Medical Sciences 8(2): 86-92.

28. Goldin SB, Wahi MM, Farooq OS, Borgman HA, Carpenter HL, et al. (2007) Student Quality-of-Life Declines During Third Year Surgical Clerkship. Journal of Surgical Research 143(1): 151-157.

29. Chan DW (1991) Depressive symptoms and depressed mood among Chinese medical students in Hong Kong. Comprehensive Psychiatry 32(2): 170-180.

30. Blanch DC, Hall JA, Roter DL, Frankel RM (2008) Medical student gender and issues of confidence. Patient Education and Counseling 72(3): 374-381

31. The USA Suicide Prevention Resource Centre (2018) A Comprehensive approach to suicide prevention. United State Department of Health and Human Services, New York, USA.

32. Eells GT, Marchell TC, CorsonRikert J, Dittman S (2012) A Public Health Approach to Campus Mental Health Promotion and Suicide Prevention. USA: Cornell University, New York, USA, p. 1-6.

33. Dooris M, Cawood J, Doherty S, Powell S (2010) HEALTHY UNIVERSITIES: Concept, Model and Framework for Applying the Healthy Settings Approach within Higher Education in England.

34. Mustafa MB, Nasir R, Yusooff F (2010) Parental Support, Personality, Self-Efficacy and Depression among Medical Students. Procedia Social and Behavioral Sciences 7: 419-424.

35. Saxena S, Jane-Llopis EVA, Hosman C (2006) Prevention of mental and behavioural disorders: implications for policy and practice. World Psychiatry 5(1): 5-14.

36. Toumbourou JW, Hemphill SA, Tresidder J, Humphreys C, Edwards J, et al. (2007) Mental health promotion and socio-economic disadvantage: lessons from substance abuse, violence and crime prevention and child health. Health promotion journal of Australia 18(3): 184-190.

37. Topp CW, Østergaard SD, Søndergaard S, Bech P (2015) The WHO-5 Well-Being Index: A Systematic Review of the Literature. Psychotherapy and Psychosomatics 84(3): 167-176.

38. Brro Ev, Balajti I, Adyny R, Kosa K (2010) Determinants of mental wellbeing in medical students. Soc Psychiat Epidemiology 45(2): 253-258.

39. Ghodasara SL, Davidson MA, Reich MS, Savoie CV, Rodgers SM (2011) Assessing student mental health at the Vanderbilt University School of Medicine. Acad Med 86(1): 116-121.

40. Ibrahim MB, Abdelreheem MH (2015) Prevalence of anxiety and depression among medical and pharmaceutical students in Alexandria University. Alexandria Journal of Medicine 51(2):167-173.

41. Goebert D, Thompson D, Takeshita J, Beach C, Bryson P, et al. (2009) Depressive symptoms in medical students and residents: a multischool study. Acad Med 84(2): 236-241.

42. Cohen D, Palmer P, Allen J, Howells S, Greene G, et al. (2013) Factors that impact on medical student well-being-Perspectives of risks. United Kingdom: School of Medicine-Cardiff University, Wales, Europe.

43. Dyrbye LN, Harper W, Moutier C, Durning SJ, Power DV, et al. (2012) A Multi-institutional Study Exploring the Impact of Positive Mental Health on Medical Students' Professionalism in an Era of High Burnout. Academic Medicine 87(8): 1024-1031.

44. Yusoff MSB (2014) Interventions on medical students' psychological health: A meta-analysis. Journal of Taibah University Medical Sciences 9(1): 1-13.

45. Kelly M (2017) Does Mindfulness practice improves the mental health and wellbeing of healthcare students? Journal of Psychiatric and Mental Health Nursing 24(1): 84-89.

46. Shekhar S (2002) Prevention and Promotion in Mental Health Geneva: Department of Mental Health and Substance Dependence, Canandaigua, USA, p. 1-37.

47. Real FJ, Zackoff MW, Davidson MA, Yakes EA (2015) Medical Student Distress and the Impact of a School-Sponsored Wellness Initiative. Medical Science Educator 25(4): 397-406.

48. Yusoff MSB (2014) Interventions on medical students? psychological health: A meta-analysis. Journal of Taibah University Medical Sciences 9(1): 1-13.

49. Fares J, Al-Tabosh H, Saadeddin Z, El-Mouhayyar C, Aridi H (2016) Stress, Burnout and Coping Strategies in Preclinical Medical Students. North American Journal of Medical Sciences 8(2): 75-81.

50. Gentile JP, Roman B (2009) Medical student mental health services: psychiatrists treating medical students. Psychiatry Edgmont $\mathrm{Pa}$ Township 6(5): 38-45.

51. Fincham JE (2008) Response Rates and Responsiveness for Surveys, Standards, and the Journal. American Journal of Pharmaceutical Education 72(2): 43.

52. Truong Thi Khanh Ha, Różycka-Tran J, Żemojtel-Piotrowska M, Piotrowski J (2013) Structural validity of the Mental Health ContinuumShort Form (MHC-SF) in Vietnam: The bifactor model of well-being. Poland: University of Gdansk - Institute of Psychology, Gdańsk, Poland.

53. Tran TD, Tran T, Fisher J (2013) Validation of the depression anxiety stress scales (DASS) 21 as a screening instrument for depression and anxiety in a rural community-based cohort of northern Vietnamese women. BMC Psychiatry 13: 24 


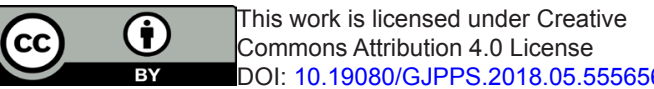
Commons Attribution 4.0 License

DOI: 10.19080/GJPPS.2018.05.555656
Your next submission with Juniper Publishers will reach you the below assets

- Quality Editorial service

- Swift Peer Review

- Reprints availability

- E-prints Service

- Manuscript Podcast for convenient understanding

- Global attainment for your research

- Manuscript accessibility in different formats

( Pdf, E-pub, Full Text, Audio)

- Unceasing customer service

Track the below URL for one-step submission https://juniperpublishers.com/online-submission.php 